\title{
Organ Donation in Children: The Next Frontier
}

\author{
Anupam SaChdeVa \\ National President, Indian Academy of Pediatrics, 2017 \\ anupamace@yahoo.co.in
}

$\mathrm{O}$ rgan transplantation involves a potentially lifesaving gift from the donor to the recipient. Sometimes organ transplantation remains only curative option available for some diseases. Advances in surgical techniques, better supportive care and in-depth knowledge of immunosuppressive therapy have resulted in improved survival rates in patients undergoing transplantation.

In recent years, pediatric solid-organ transplantation has evolved into a well-established, usually successful procedure, with the gap between available organs and demand still growing. As protocols for organ donation were developed for adults, potential pediatric donors are lost to the donation pool [1]. Transplantation of Human Organs Act was passed in India in 1994, making it possible to retrieve organs from brain-dead donors, but only few pediatric donors are there so far. Unforeseen death, religious and cultural beliefs, fear of mutilation, and families not being aware about organ donation lead to denial for donation. Along with other issue like death certification and ethical dilemmas, parental consent remain the most important hurdle for organ donation in children [2]. It has been shown that supportive behaviors from medical staff based on training and educational programs, and treating parents with dignity and respect are essential predictors for getting consent. Practitioners involved in pediatric and neonatal organ transplantation should apply the four principles of biomedical ethics: autonomy, nonmaleficence, beneficence and justice [3].

While diseases of heart, liver and kidney are common in children, there are no data on requirement of organs for children in India. Brain death is the permanent and irreversible loss of brainstem and cortical function. Organs procured from brain dead pediatric donors is a clinical reality for heart, liver, bowel and lung transplantation [4]. While majority of organ transplants in the world are done from deceased donors after brain death, most of our programs are based on living donors. Organ donation after brain death and more rarely donation after circulatory death are the best hope for saving more lives in India. A single donor can save several lives by donating organs like heart, lungs, kidneys, liver and the small intestine. After any death, tissues like cornea, skin and bones may be donated.

There is a poor organ donation rate in India $(0.26$ per million), compared to other countries such as USA ( 26 per million), Spain (35.3 per million) and Croatia (36.5 per million). With a 1 per million-donation rate, India would have 1100 organ donors or 2200 kidneys, 1100 hearts, 1100 livers, 1100 pancreas and 2200 eyes. This should take care of almost all current demand for organs. Following steps can be taken to increase the number of organ donations in India:

1. Promotion of pediatric cadaver organ donation programme

2. Support of the media in promoting awareness among the public, and their support towards the programme

3. Increasing awareness among the medical fraternity about the rules and procedures related to organ transplantation

4. Increasing the number of trained transplant coordinators and organ procurement organizations

5. Creating departments in each state of India, undertaking the policy formulation with respect to organ transplantation

6. Cooperation between public and private hospitals

7. Soliciting help from non-governmental organization for capacity building and creating awareness among the public and in hospitals

8. Creating pediatric organ recipient registries so as to ensure maximum utilization of organs for pediatric transplantation

\section{REFERENCES}

1. Workman JK, Myrick CW, Meyers RL, Bratton SL, Nakagawa TA. Pediatric organ donation and transplantation. Pediatrics. 2013;131:e1723-30.

2. Jacoby L, Jaccard J. Perceived support among families deciding about organ donation for their loved one: donor vs nondonor next of kin. Am J Crit Care. 2010;19:e52-61.

3. Beauchamp TL, Childress JF. Principles of Biomedical Ethics. New York: Oxford University Press, 2009.

4. Magee JC, Bucuvalas JC, Farmer DG, Harmon WE, Hulbert-Shearon TE, Mendeloff EN. Pediatric transplantation. Am J Transplant. 2004;4(suppl 9):54-71. 